\title{
Lipases: particularly effective biocatalysts for cosmetic active ingredients
}

\author{
Florent Yvergnaux ${ }^{*}$ \\ Bioeurope, Solabia Group, Route d'Oulins, 28260 Anet, France
}

Received 1 February 2017 - Accepted 10 March 2017

\begin{abstract}
Enzymes are the tools of choice in the on-going quest for non-pollutant processes to discover molecules for use in skin products. Amongst these biocatalysts, lipases offer considerable potential in terms of ingredient development and are of interest in skin dermocosmetic formulations possessing sensory or biological activities. Lipases have been studied for around thirty years and, in most cases, these enzymes function under what are deemed to be mild conditions, displaying remarkable efficacy particularly in terms of selectivity. This particularly effective strategy will be illustrated through typical synthesis, demonstrating how ester or amide active ingredients are obtained.
\end{abstract}

Keywords: lipase / cosmetic ingredient / ester / amide

Résumé - Les lipases : des biocatalyseurs particulièrement efficaces pour le développement d'ingrédients actifs cosmétiques. Dans la recherche constante de procédés non polluants pour l'obtention de molécules à visée cutanée, les enzymes constituent des outils de choix. Parmi ces biocatalyseurs, les lipases sont des options très importantes pour le développement d'ingrédients avec un intérêt pour des applications en formulation dermocosmétiques possédant des activités sensorielles ou biologiques. Les lipases ont été étudiées depuis une trentaine d'années et dans la plupart des cas, ces enzymes fonctionnent dans des conditions que l'on qualifie de douces avec des efficacités remarquables notamment liées à leurs différentes sélectivités. Cette stratégie particulièrement efficace sera illustrée par quelques exemples de synthèse d'ingrédients actifs de type esters ou amides.

Mots clés : lipase / ingrédient cosmétique / ester / amide

\section{Introduction}

Cosmetic developments aimed at the discovery of increasingly high-performance active ingredients also generate molecules that are often difficult to obtain. Moreover, research into environmentally friendly methodology (see the increase in green chemistry in this area) is permanently steering synthesis towards increasingly cleaner technologies. The use of enzymes is one such alternative, which is entirely appropriate. The biocatalyst, for instance, which lowers the thermodynamic barrier separating the formed product from the initial substrate, substantially limits energy expenditure compared to chemical synthesis.

Another advantage of these enzymes is their ability to function under mild conditions (temperature, $\mathrm{pH}$, concentration, etc.). This is a more environmentally friendly approach because of the reduction in toxic by-products and the use of either solvent-free reactions or reactions in an aqueous phase. Lipases, which possess these qualities, and ease of use are the

\footnotetext{
* Correspondence: florent.yvergnaux@solabia.fr
}

tools that are particularly sought after when synthesising active ingredients in the skin sector.

\section{Discussion}

Lipases possess specific characteristics for developing active ingredients because they target extremely varied substrates.

At the outset, a lipase was a triacylglycerol hydrolase and the definition given in 1958 by Sarda and Desnuelle was as follows:

"a lipase is a carboxyl esterase, which specifically hydrolyses the acyl-glycerol substrate" (Sarda and Desnuelle, 1958).

This definition, which has been around for more than half a century, has become too restrictive because these biocatalysts can be used with numerous substrates for various applications.

These enzymes therefore constitute a group of biocatalysts with an extremely important potential for the extraction, purification and development of numerous molecules. Another advantage of these enzymes is their ability to function in media which can be aqueous to varying degree (Kamal et al., 2013). 
These lipases react like other catalysts in terms of both hydrolysis and synthesis (Zaks and Klibanov, 1985). The terms of the reaction are defined by thermodynamic factors. The stability of the products obtained depends on the temperature of the reaction or reagent concentration for instance. As mentioned previously, lipases are particularly suitable for working not only with raw or refined starting materials but also with sophisticated substrates or unstable molecules because they react under conditions which are defined as mild. For example, the reaction temperature is generally between $25^{\circ} \mathrm{C}$ and $40^{\circ} \mathrm{C}$. Furthermore, lipases have different selectivities (typoselectivity or structural selectivity, regioselectivity and stereoselectivity) which make them particularly attractive synthesis tools (Kourist et al., 2014). In fact, whilst developing ingredients for skin care products, compared to chemical syntheses, this makes the compounds produced more stable with very few secondary compounds if, indeed, any. In fact, these lipases combined with important energy gains can be recycled easily, especially in an immobilised form. All of these advantages are extremely beneficial for the environment. From an industrial perspective, lipases are used in an immobilised form, which means that they can easily be recycled (AnsorgeSchumacher and Thum, 2013). This is clearly evident from the stability of the compounds generated as shown in the hydrolysis of oil with a high polyunsaturated fatty acid content such as blackcurrant seed oil (Wille, 1996). The reaction occurred in just $4 \mathrm{~h}$ with a $\mathrm{pH}$ of 6.88 and at a slightly elevated temperature of just $30{ }^{\circ} \mathrm{C}$. This was compared to the chemical saponification technique and the results on the stability of polyunsaturated fatty acids were very much in favour of enzyme technology because peroxide value is 7.9 by chemical process against 1.4 by enzymatic process.

In terms of synthesis, a few simple examples also show the potential of lipases. An ester such as cetyl ricinoleate used in cosmetic formulations was synthesised with good yields $(93 \%)$ via the enzyme route with very few contaminants compared to chemical synthesis (61\%) (Hills, 2003).

This strategy is currently used to obtain numerous molecules obtained from fatty acids. These include structured triglycerides, esters used in perfumes and flavourings and antioxidant derivatives (Dhake et al., 2013).

Villeneuve and his team also used various polyphenolic acids such as dihydrocaffeic acid, via lipases (Figueroa-Espinoza and Villeneuve, 2005). Unlike chemical synthesis, the enzyme reaction occurred with very good yields only between the polyphenolic acid in question and various aliphatic alcohols like butanol, hexadecanol and octyl 9-octadecanol. Recently different flavonoid esters were described linked to their properties (De Araujo et al., 2017). Other compounds developed for skin applications such as ascorbic acid esters, for instance, were also synthesised easily using lipases (Song and Wei, 2002).

Sugar esters are some of the molecules mainly worked for use in skin formulations. In fact, these compounds are used as non-ionic surfactants in particular. Specific reference can thus be made to compounds such as 6-O-acyl glucose or 6-O-acyl sucrose (Ferrer et al., 2005). Excellent biodegradability is one of the acknowledged benefits of these molecules (Baker et al., 2000). In addition, they are produced from inexpensive, renewable raw materials. From an application standpoint, it is important to add that they are odourless and non-toxic. The advantages of enzyme synthesis compared to chemical synthesis have been perfectly described in the literature (Piccicuto et al., 2001). As regards the use of enzymes, the excellent selectivity of biocatalysts has been established with reactions that occur under mild and natural conditions. This leads to straightforward purification and product composition is perfectly defined. The disadvantages outlined compared to chemistry include more expensive syntheses with variable yields depending on the sugars and fatty acids used. The impact on the formulations of various sucrose esters with extremely long-chain fatty acids have also been described recently (Wei et al., 2015). The importance of obtaining monoesters with excellent selectivity has also been shown. Consequently, the benefit of lipase synthesis is superior to that obtained with conventional chemistry despite the additional cost incurred. According to a recent publication, for the same type of application using lipases, increased viscosity was recorded on esterification of maltodextrin obtained from tapioca (Udomrati and Gohtani, 2014). The use of these biocatalysts is also regularly described in the area of ingredients presenting biological activities. Thus a conjugated fatty acid with triple instauration such as punicic acid was esterified with a phenol alcohol such as tyrosol obtained from olive oil. This tyrosyl punicate is used in cellulite reduction (Yvergnaux and Couturier, 2010). Contrary to chemical synthesis, enzyme reaction produces excellent yields and perfect selectivity.

An ester between linoleic acid and piperonyl alcohol was recently described with whitening properties (Yvergnaux et al., 2012). The mild operating conditions did not denature linoleic acid (Fig. 1).

Regardless of these esterification reactions, lipases can lead to other types of reaction such as amidation (Couturier et al., 2009).

Ceramides are natural molecules that play an important role in the skin and have basic functions in maintaining the skin barrier (Choi and Maibach, 2005). Ceramides are also involved in communication, differentiation and cell proliferation mechanisms. These lipids are found in increasingly larger quantities, the closer they are to the surface of the skin. During the ageing process, for instance, the quantity of these compounds tends to decrease which frequently causes the skin to dry out.

These molecules are relatively complex and their synthesis has been described via the enzyme route from sphingosine or phytosphingosine (Smeets et al., 1994). Nevertheless, these molecules, which are identical to the natural compounds found in the stratum corneum, are rather costly, which limits their use to considerable extent. A ceramide analogue possessing interesting properties in terms of dermal cosmetic applications was easily synthesised by combining the specific features of lipases through amidification followed by esterification (Lassalle and Yvergnaux, 2004) (Fig. 2).

Biological results highlighting the skin's ability to restructure the lipid cement contained in the stratum corneum were validated in one study. During this study, volunteers applied a cream containing $1 \%$ of this structural ceramide analogue versus the same placebo formulation twice daily (15 in each group). The structure of the various layers of the stratum corneum after stripping was revealed by electron microscopy. This showed that the use of this compound obtained solely through enzyme synthesis using lipase led to excellent restructuring of the lipid cement since this result was observed in $100 \%$ of the volunteers who applied the formula containing the biotechnological ceramide analogue compared to the placebo formulation (Figs. 3 and 4). 


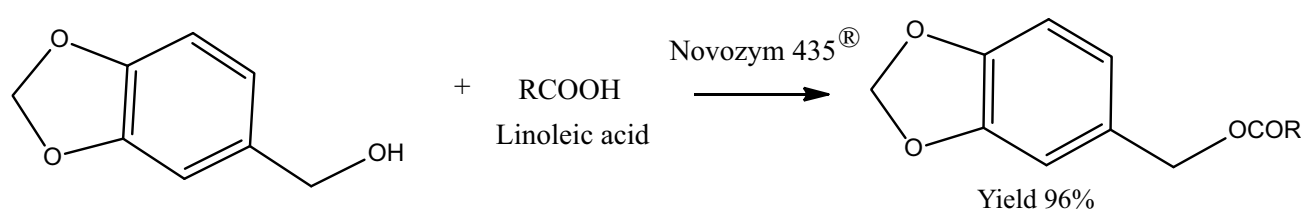

Fig. 1. Synthesis of piperonyl linoleate by enzymatic process with lipase.

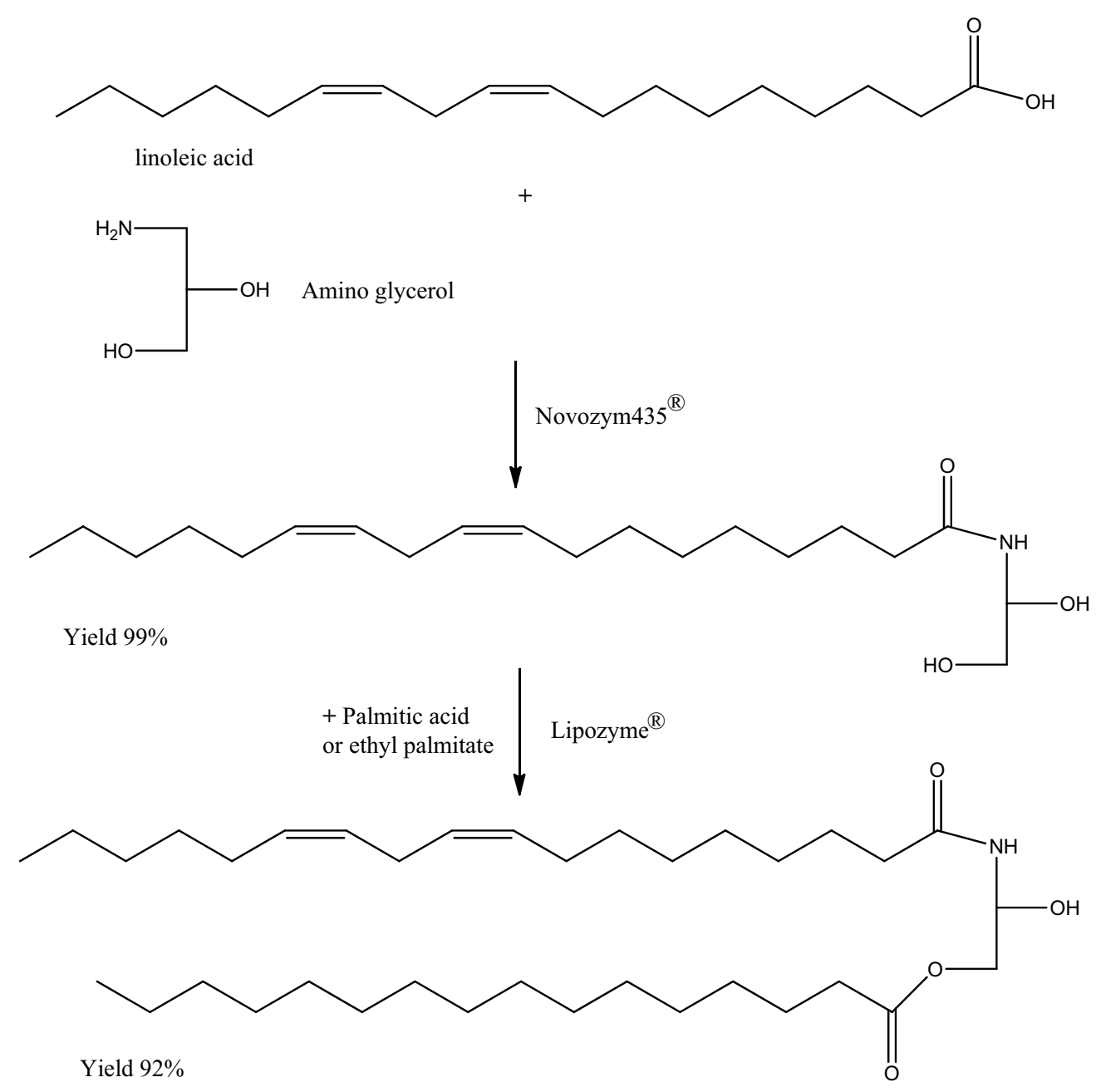

Fig. 2. Enzymatic synthesis of ceramide analogue with two selective lipases.

\section{Conclusion}

In recent years, the use of lipases to hydrolyse or synthesise compounds under mild conditions has become established. By virtue of their different selectivities and ease of use, these biocatalysts are tools of choice in obtaining active, albeit potentially fragile molecules. These selectivities pave the way to compounds with more lipophilic characteristics or vice versa.

It is particularly interesting to note that, under certain conditions, these catalysts offer a natural approach compared to a chemical catalyst.
In hydrolysis or synthesis, lipases often compete against chemical catalysts to generate molecules with a high added value. The use of this biotechnological process is a particularly effective strategy that does not, anecdotally, involve a purification stage because the molecules obtained are already in a highly pure form for the most part. Finally, environmentally friendly reaction conditions are a vital asset in developing skin cosmetics. Research into new lipases of different origins and further developments in terms of application and activity herald a rosy future for these biocatalysts.

Conflicts of interest. The author declares that he has no conflicts of interest in relation to this article. 

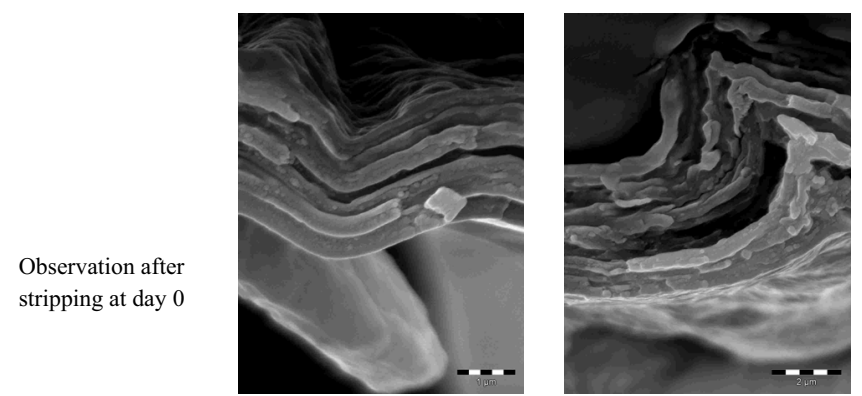

Observation after stripping at day 14
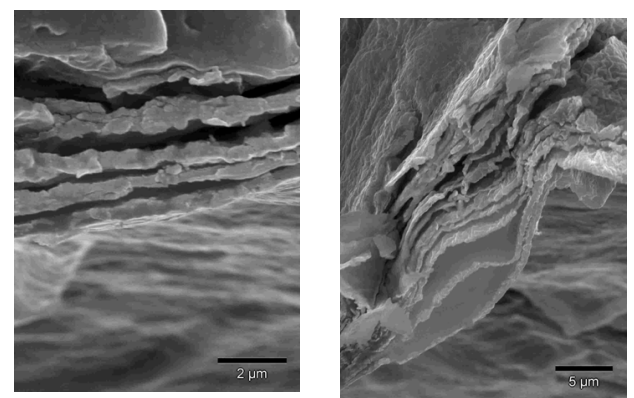

Fig. 3. Example of observations by electron microscopy with a placebo cream. No modification of the observations after stripping after 14 days.

Observation after stripping at day 0
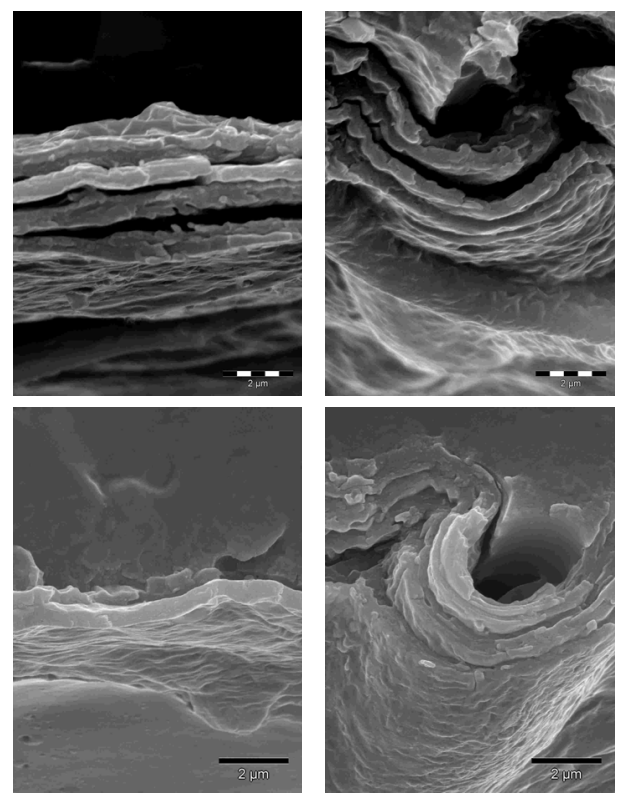

Fig. 4. Example of observations by electronic microscopy with a cream containing $1 \%$ of an analogue of ceramide. After 14 days a very good cohesion of the layers of the stratum corneum are seen.

\section{References}

Ansorge-Schumacher MB, Thum O. 2013. Immobilised lipases in the cosmetic industry. Chem Soc Rev 42: 6475-6490.
Baker IJA, Matthews B, Suares H, et al. 2000. Sugar fatty acid ester surfactants: structure and ultimate aerobic biodegradability. $J$ Surfactants Deterg 3: 1-11.

Choi MJ, Maibach HI. 2005. Role of ceramides in barrier function of healthy and diseased skin. Am J Clin Dermatol 6: 215-223.

Couturier L, Taupin D, Yvergnaux F. 2009. Lipase-catalyzed chemoselective aminolysis of various aminoalcohols with fatty acids. J Mol Catal B: Enzym 56: 29-33.

De Araujo MEMB, Franco YEM, Messias MCF, Longato GB Pamphile JA, Carvalho PDO. 2017. Biocatalytic synthesis of flavonoid esters by lipases and their biological benefits. Planta Med 83: 7-22.

Dhake KP, Thakare DD, Bhanage BM. 2013. Lipase: a potential biocatalyst for the synthesis of valuable flavor and fragrance ester compounds. Flavour Fragr J 28: 71-83.

Ferrer M, Soliveri J, Plou FJ et al. 2005. Synthesis of sugar esters in solvent mixtures by lipases from Thermomyces lanuginosus and Candida Antarctica B, and their antimicrobial properties. Enzyme Microb Technol 36: 391-398.

Figueroa-Espinoza MC, Villeneuve P. 2005. Phenolic acids enzymatic lipophilization. J Agric Food Chem. 53: 2779-2787.

Hills G. 2003. Industrial use of lipases to produce fatty acid esters. Eur J Lipid Sci Technol 105: 601-607.

Kamal MdZ, Yedavalli P, Deshmukh MV, Rao NM. 2013. Lipase in aqueous-polar organic solvents: activity, structure and stability. Protein Sci 22: 904-915.

Kourist R, Hollmann F, Nguyen GS. 2014. Lipases as sustainable biocatalysts for the sustainable industrial production of fine chemicals and cosmetics. JSM Biotechnol Bioeng 2: 1029-1040.

Lassalle L, Yvergnaux F. 2004. New method for synthesizing ceramide-type compounds. Patent WO2004108659, 40 p.

Piccicuto S, Blecker C, Brohee JC, et al. 2001. Les esters de sucres : voies de synthèse et potentialités d'utilisation. Biotechnol Agron Soc Environ 5: 209-219.

Sarda L, Desnuelle P. 1958. Action of pancreatic lipase on emulsified esters. Biochim Biophys Acta 30: 513-521.

Smeets JWH, De Pater RM., Lambers JWJ. 1994. Enzymatic synthesis of ceramides and hybrid ceramides. Patent WO 9426919, $17 \mathrm{p}$.

Song QX, Wei DZ. 2002. Study of vitamin C ester synthesis by immobilized lipase from Candida sp. J Mol Catal B: Enzym 18: 261-266.

Udomrati S, Gohtani S. 2014. Enzymatic esterification of tapioca maltodextrin fatty acid ester. Carbohydr Polym 99: 379-384.

Wei W, Feng F, Perez B, Dong M, Guo Z. 2015. Biocatalytic synthesis of ultra-long-chain fatty acid sugar alcohol monoesters. Green Chem 17: 3475-3489.

Wille HJ. 1996. Process for hydrolysis of polyunsaturated fatty acid triglyceride. Patent E.P. 071498, 6 p.

Yvergnaux F, Couturier L. 2010. Punicic acid derivatives and use thereof in cosmetic and/or dermatological composition for weight loss purposes. Patent WO2010094992, $31 \mathrm{p}$.

Yvergnaux F, Vardon P, Saguet T, Couturier L. 2012. Composition, useful as antiaging and depigmenting cosmetic compositions, comprises piperonyl carboxylic acid ester compound in combination with carrier or vehicle. Patent FR2967055, 31 p.

Zaks A, Klibanov AM. 1985. Enzyme-catalyzed processes in organic solvents. Proc Natl Acad Sci USA 82: 3192-3196.

Cite this article as: Yvergnaux F. 2017. Lipases: particularly effective biocatalysts for cosmetic active ingredients. OCL 24(4): D408. 